\title{
Effect of the topical application of an ethanol extract of quince seeds on the development of atopic dermatitis-like symptoms in NC/Nga mice
}

\author{
Takeshi Kawahara ${ }^{1,2^{*}}$, Kanako Tsutsui ${ }^{1}$, Eri Nakanishi ${ }^{1}$, Toshifumi Inoue ${ }^{3}$ and Yasunori Hamauzu ${ }^{1}$
}

\begin{abstract}
Background: Quince (Cydonia oblonga Miller) is a deciduous shrub belonging to the Rosaceae family. Quince seed extract has long been used as a cosmetic ingredient for its moisturizing effect. However, little is known about whether quince seed extract has therapeutic effects on keratinocyte-associated skin inflammation.

Methods: In the present study, we investigated the effect of the topical application of ethanol extract of quince seeds (QSEtE) on atopic dermatitis (AD) symptoms in NC/Nga mice. The direct effect of QSEtE on keratinocytes was evaluated using the human keratinocyte cell line HaCaT.

Results: The preliminary application of QSEtE markedly reduced house dust mite allergen-induced skin lesions. The expression of thymus- and activation-regulated chemokine (TARC) in dorsal skin was downregulated. QSEtE directly suppressed the expression and production of TARC in HaCaT cells.

Conclusions: The results suggest that the topical application of QSEtE is effective in preventing the onset of and ameliorating the atopic symptoms of keratinocyte-associated skin inflammation by suppressing TARC production in keratinocytes.
\end{abstract}

Keywords: Quince seed, Cydonia oblonga, Atopic dermatitis, Keratinocyte, Thymus- and activation-regulated Chemokine

\section{Background}

Quince (Cydonia oblonga Miller) is a deciduous shrub that belongs to the Rosaceae family and has been mainly cultivated in Asia and areas of the Mediterranean since ancient times [1]. Although quince fruit is not edible owing to its hard, tough and fibrous consistency, it has been used in honeydew and liquors for its pleasant aroma [2]. In addition, peculiar mucilage, which is a mixture of cellulose and water-soluble polysaccharides, is obtained from quince seeds by soaking them in water [3]. The mucilage is reported to have proliferation-

\footnotetext{
* Correspondence: tkawafb@shinshu-u.ac.jp

'Department of Sciences of Functional Foods, Graduate School of

Agriculture, Shinshu University, 8304 Minamiminowa, Kamiina, Nagano

399-4598, Japan

${ }^{2}$ Research Center for Fungal \& Microbial Dynamism, Shinshu University, 8304

Minamiminowa, Kamiina, Nagano 399-4598, Japan

Full list of author information is available at the end of the article
}

enhancing effect on skin fibroblasts [4], healing effects on incised wounds [5], and protective effects against dermal toxicity caused by T2-toxin [6]. Therefore, the mucilage from quince seeds has long been used as a cosmetic ingredient, known as "quince seed extract", to maintain the barrier function of the skin [7]. However, little is known about the physiological effect of quince seed extract on skin keratinocytes, and the associated onset of atopic side effects on the skin.

Atopic dermatitis (AD) is a chronic inflammatory skin disease associated with intense pruritus and a series of exacerbations and remissions [8]. AD is recognized as a type I and type IV complex according to the Coombs and Gell classification system [9]. Both T-helper (Th2) type immunologic reactions and T-cell-mediated delayed hypersensitivity are involved in AD. In addition, it has been recognized that the expression of various 
inflammatory chemokines produced by keratinocytes plays important roles in the pathogenesis of $\mathrm{AD}$ [10].

In the present study, we aimed to evaluate whether quince seeds have a suppressive effect on the incidence and development of allergic inflammation in the skin. For this purpose, an AD model mouse and a human keratinocyte cell line were used.

\section{Methods}

\section{Preparation of QSEtE}

The fruits of quince 'Smyrna' were purchased from the fruit farm in the Minamiminowa-mura area of Nagano, Japan and were formally surveyed and identified at the Laboratory for Postharvest Science and Functional Properties of Fruits and Vegetables. Twenty grams of seeds was separated from the fruits and immersed in $80 \mathrm{~mL}$ ethanol. Then, extraction was performed for 1 week at room temperature. The ethanol extract was then filtered using a Buchner funnel with filter paper discs to remove insoluble residues. Then, the extract was dissolved in water after removal of ethanol and lyophilized using an FD-5 N freeze dryer (EYELA) to obtain powdered QSEtE. We re-constituted QSEtE in ethanol at the indicated concentrations and sterilized using a $0.2-\mu \mathrm{m}$ pore size cellulose acetate membrane filter (Advantec, Tokyo, Japan) before use.

\section{Mice}

Specific pathogen-free, female NC/Nga mice, aged 10 weeks, with 19-23 g body weight were purchased from Charles Liver Laboratories Japan, Inc. (Kanagawa, Japan). The animals were housed at $23 \pm 3{ }^{\circ} \mathrm{C}$ under a 12-h light/dark cycle and acclimatized for 7 days in laboratory condition before experiments. Food and water were provided ad libitum. All animal protocols were approved by the Committee for Animal Experiments of Shinshu University (Matsumoto, Japan).

\section{Induction of dermatitis}

A schematic procedure of the topical application of QSEtE to NC/Nga mice is shown in Fig. 1. At the start of the experiment, mice were randomly divided into the following three groups ( $n=6$ for each group): ethanol-treated group (vehicle), $0.1 \%(\mathrm{w} / \mathrm{v})$ QSEtE/ethanol-treated group $(0.1 \%$ QSEtE), and $1.0 \%(\mathrm{w} / \mathrm{v})$ QSEtE/ethanol-treated group (1.0\% QSEtE). The experimental unit is a cage with a single animal. AD-like skin lesions were induced by topical application of Biostir-AD (Biostir, Kobe, Japan), a hydrophilic petrolatum-based ointment-containing extract of house dust mite (Dermatophagoides farinae), according to the manufacturer's instructions. The hair on the upper dorsal skin and the back of the ears of mice was shaved under isoflurane anaesthesia, and $100 \mu \mathrm{L}$ of $4 \%(\mathrm{w} / \mathrm{v})$ sodium dodecyl sulphate was applied to shaved skin for barrier disruption. After $3 \mathrm{~h}, 100 \mu \mathrm{L}$ ethanol (vehicle), 0.1\% QSEtE in ethanol, or $1.0 \%$ QSEtE in ethanol was applied to the area twice a week. Then, the following week, Biostir-AD was applied to the skin area immediately after QSEtE application. The application of the test substrate and Biostir-AD was repeated twice weekly for a further 3 weeks. On day 28 of the experiment, mice were sacrificed by cervical dislocation. Then, the ear and dorsal skin were harvested for histological analyses and analysis of gene expression, respectively. Any clinical signs related to toxicity, such as remarkable loss of body weight, were monitored in all groups of animals throughout the course of experiment.

\section{Evaluation of the severity of skin lesions}

The severity of dermatitis was evaluated according to a previously described method [11]. Briefly, the development of erythema haemorrhage, scarring dryness, oedema and excoriation erosion was scored as 0 (none), 1 (mild), 2 (moderate) and 3 (severe). The sum of the individual scores was taken as the dermatitis score.

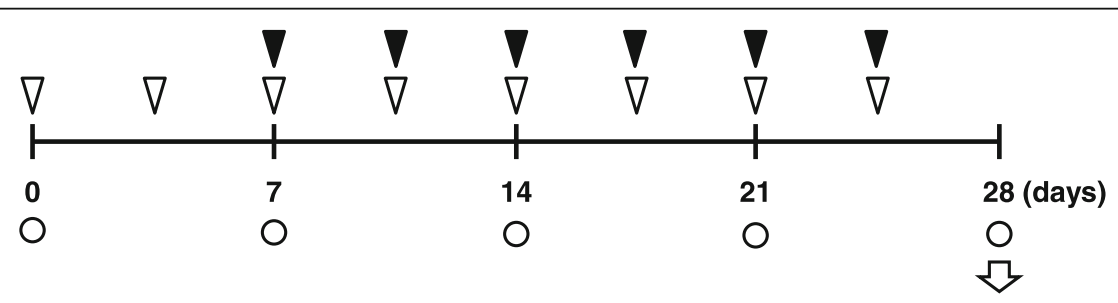

$\nabla$ Topical application of QSEtE/ethanol ( $0.1 \%$ or $1.0 \%)$ or ethanol (vehicle)

$\nabla$ Topical application of Biostir-AD

Scoring of atopic symptoms

V Harvesting of skin

Fig. 1 Experimental design of QSEtE application. To induce AD-like symptoms, Biostir-AD was topically applied to the skin of NC/Nga mice twice weekly for 3 weeks. Mice were either treated with QSEtE dissolved in ethanol (0.1 or 1.0\% QSEtE), or ethanol alone (vehicle) twice weekly 1 week prior to the application of Biostir-AD application 


\section{Histopathological studies}

The harvested ear of mice was immediately fixed in $10 \%$ $(\mathrm{v} / \mathrm{v})$ neutral buffered formalin and left for $48 \mathrm{~h}$. Then, the fixed ear was sliced and embedded in paraffin, sectioned, deparaffinised and rehydrated at the Biopathology Institute Co., Ltd. (Oita, Japan). The processed sections were either subjected to hematoxylin and eosin staining to evaluate oedema, or subjected to toluidine blue staining to evaluate infiltrated mast cells.

\section{Cells}

A human keratinocyte cell line, $\mathrm{HaCaT}$, was purchased from Cell Lines Service GmbH (Eppelheim, Germany). $\mathrm{HaCaT}$ cells were cultured using high glucose Dulbecco's modified Eagle's medium (Wako Pure Chemical Industries, Ltd., Osaka, Japan) supplemented with 10\% heatinactivated foetal bovine serum (Equitech-Bio, Kerrville, TX, USA), $2 \mathrm{M}$ L-glutamine, $100 \mathrm{U} / \mathrm{mL}$ penicillin $\mathrm{G}$ and $100 \mu \mathrm{g} / \mathrm{mL}$ streptomycin. Cells were passaged using conventional procedures with $0.05 \%$ trypsin in a humidified atmosphere of $5 \% \mathrm{CO}_{2} / 95 \%$ air at $37{ }^{\circ} \mathrm{C}$.

\section{Induction of thymus and activation-regulated chemokine (TARC)}

TARC was induced from HaCaT cells according to the method of Sumiyoshi et al. [12]. Briefly, HaCaT cells $\left(2.5 \times 10^{5}\right.$ cells $/ 1 \mathrm{~mL} /$ well $)$ were seeded in a 24-well tissue culture plate (Falcon; Corning Incorporated, Corning, NY, USA) and cultured with the aforementioned concentrations of QSEtE for $24 \mathrm{~h}$. The cells were then stimulated with $10 \mathrm{ng} / \mathrm{mL}$ human recombinant tumour necrosis factor (TNF)- $\alpha$ (PeproTech, Rocky Hill, NJ, USA) and $10 \mathrm{ng} / \mathrm{mL}$ human recombinant interferon (IFN)- $\gamma$ (PeproTech). After $6 \mathrm{~h}$, the cells were subjected to quantitative reverse transcription-polymerase chain reaction (qRT-PCR). The culture supernatant was collected $24 \mathrm{~h}$ after stimulation and stored at $-80{ }^{\circ} \mathrm{C}$ for enzyme-link immunosorbent assay (ELISA).

\section{qRT-PCR}

TARC mRNA expression in $\mathrm{HaCaT}$ cells was analysed by qRT-PCR. Total RNA was extracted from cells using TRI reagent (Merck Millipore, Darmstadt, Germany) according to the manufacturer's protocol. The extracted RNA $(1 \mu \mathrm{g})$ was reverse transcribed in a thermal cycler (PTC-200; MJ Research, Waltham, MA, USA) with $1 \mathrm{mM}$ dNTP, $2.5 \mathrm{U} /$ $\mu \mathrm{L}$ M-MLV reverse transcriptase (Thermo Fisher Scientific, Roskilde, Denmark) and $10 \mathrm{pmol} / \mu \mathrm{L}$ random primer at $42{ }^{\circ} \mathrm{C}$ for $50 \mathrm{~min}$. qRT-PCR was performed using $0.5 \mu \mathrm{g}$ cDNA with SYBR Premix Ex Taq II (Takara Bio, Otsu, Japan) and $10 \mathrm{pmol} / \mu \mathrm{L}$ primers. The primer sequences for human TARC (GenBank: NM_002987.2) were designed as 5' -TTTGAGCTCACAGTGTCACC-3' (forward) and 5' GGAGTCTCTGTGTGCAGGTC-3' (reverse), and were complementary to $18-37$ and $110-91$, respectively. The primer sequences for human glyceraldehyde-3-phosphate dehydrogenase (GAPDH; GenBank: AF261085.1) were designed as 5' - CTGCTCCTCCTGTTCGACAG-3' (forward) and 5' - GCGCCCAATACGACCAAATC-3' (reverse), and were complementary to 33-52 and 151-132, respectively. PCR comprised 1 cycle of preheating $\left(95^{\circ} \mathrm{C}\right.$, $10 \mathrm{~min}), 40$ cycles of denaturation $\left(95^{\circ} \mathrm{C}, 10 \mathrm{~s}\right)$, and primer annealing and extension $\left(55^{\circ} \mathrm{C}, 30 \mathrm{~s}\right)$ using an Eco Real Time PCR System (Illumina, San Diego, CA, USA). Results were analysed with the $\Delta \Delta \mathrm{Ct}$ method using Eco system software (Illumina). The amounts of PCR products were normalised to the expression level of GAPDH mRNA.

\section{ELISA}

IgE level in mice serum and TARC produced by $\mathrm{HaCaT}$ cells in culture supernatant were measured using sandwich ELISA. The detailed procedure to measure IgE was described previously [13]. To measure TARC, $50 \mu \mathrm{L}$ of $2 \mu \mathrm{g} / \mathrm{mL}$ mouse anti-human TARC ( $\mathrm{R} \& \mathrm{D}$ Systems, Minneapolis, MN, USA) dissolved in $0.1 \mathrm{M}$ carbonate buffer ( $\mathrm{pH}$ 10.0) was added to each well of a 96-well Nunc Immuno Plate MaxiSorp (Thermo Fisher Scientific) and incubated at $30{ }^{\circ} \mathrm{C}$ for $2 \mathrm{~h}$. Each well was washed three times with phosphate-buffered saline (PBS; $\mathrm{pH} 7.2$ ) containing $0.05 \%$ Tween 20 (PBST) and then post-coated with $300 \mu \mathrm{L}$ 1\% Block Ace (DS Pharma Biomedical, Osaka, Japan) in $0.1 \mathrm{M}$ sodium carbonate buffer ( $\mathrm{pH} 10.0)$ at $4{ }^{\circ} \mathrm{C}$ overnight. After the plates were washed three times with PBST, $50 \mu \mathrm{L}$ culture supernatant or a standard solution optimally diluted with PBS was added to each well and incubated at $37{ }^{\circ} \mathrm{C}$ for $2 \mathrm{~h}$. Recombinant human TARC (Shenandoah Biotechnology, Warwick, PA, USA) was used as the standard. The plates were then washed 3 times with PBST. Next, $100 \mu \mathrm{L}$ of $4 \mu \mathrm{g} / \mathrm{mL}$ biotinylated goat anti-human TARC ( $\mathrm{R} \& \mathrm{D}$ systems) was added to each well and incubated at $37{ }^{\circ} \mathrm{C}$ for $30 \mathrm{~min}$. After five washes with PBST, the wells were filled with $100 \mu \mathrm{L}$ of $2 \mu \mathrm{g} / \mathrm{mL}$ horseradish peroxidaseconjugated streptavidin (BD Biosciences, Franklin Lakes, NJ, USA) and incubated at $37{ }^{\circ} \mathrm{C}$ for $30 \mathrm{~min}$. Then, the wells were washed five times with PBST, after which $100 \mu \mathrm{L}$ TMB Microwell Peroxidase Substrate System (Kirkegaard \& Perry Laboratories, Gaithersburg, MD, USA) was added to each well, and the plate was incubated at $30{ }^{\circ} \mathrm{C}$ for $15 \mathrm{~min}$. The reaction was stopped by adding $100 \mu \mathrm{L} 1 \mathrm{M}$ phosphoric acid. The absorbance at $450 \mathrm{~nm}$ was measured on an iMark microplate reader (Bio-Rad Laboratories, Hercules, CA, USA).

\section{Statistical analysis}

The results obtained in the animal study were analysed using a Mann-Whitney $U$ test. The results obtained in 
the cell culture study were statistically analysed using a two-tailed Student's t-test. P-values less than 0.05 were considered to indicate a statistically significant difference.

\section{Results}

Effect of QSEtE treatment on Biostir-AD-induced skin lesions in $\mathrm{NC} / \mathrm{Nga}$ mice

QSEtE was obtained from the seeds of quince with a $0.3 \%$ yield on wet weight basis. To examine the effects of QSEtE on AD-like skin lesions in vivo, NC/Nga mice were administered different doses of QSEtE prior to Biostir-AD application. At 1 week after the application of QSEtE, no observable skin irritation was identified. Repeated application of Biostir-AD macroscopically resulted in AD-like lesions on the dorsal skin of mice after 3 weeks. The average clinical severity scores for each group on day 28 were as follows: $8.2 \pm 3.9$ (vehicle), 2.8 \pm 1.7 (0.1\% QSEtE), and $0.5 \pm 0.8$ (1.0\% QSEtE) (Fig. 2). Total clinical severity scores in QSEtE-treated groups dose-dependently decreased compared with the scores of vehicle-treated mice. In particular, small lesions of the skin were observed in the $1.0 \%$ QSEtE-treated group throughout the entire experimental period. Among the three groups, there were no noticeable adverse effects and no significant differences in body weight gain (data not shown).

AD-like symptom, such as epidermal thickening and infiltration of inflammatory cells in the dermis, were observed on day 28 of the experiment (Fig. 3a). QSEtEtreated mice showed a marked reduction in the degree of mast cell infiltration in the skin compared to that reported for the vehicle-treated mice (Fig. 3b).

\section{a}

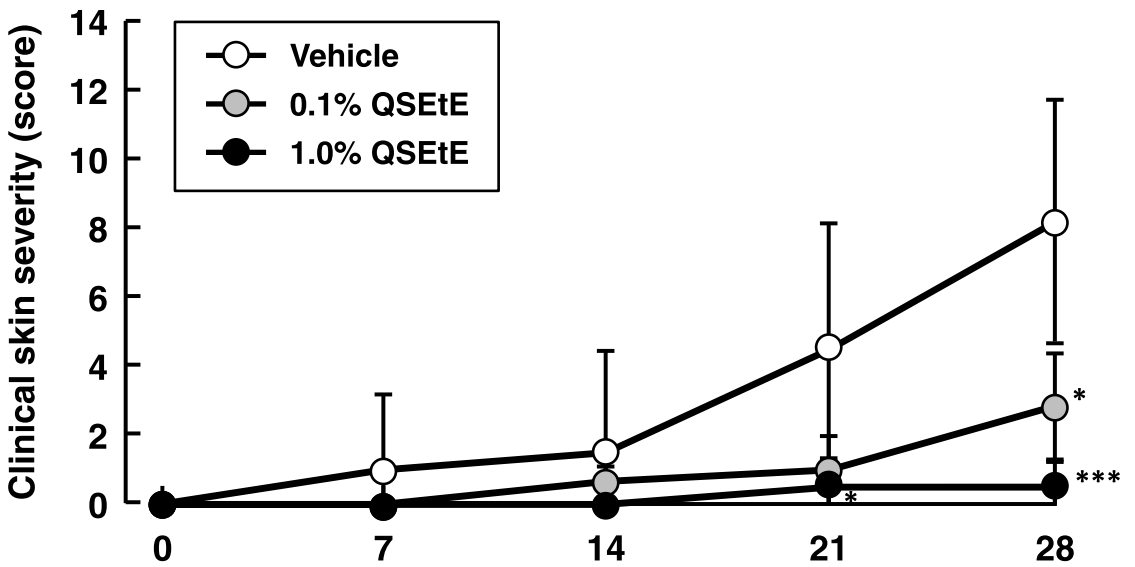

Experimental period (days)

b

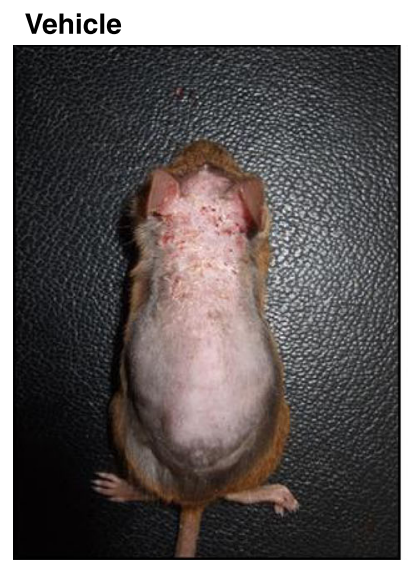

$0.1 \%$ QSEtE

$1.0 \%$ QSEtE
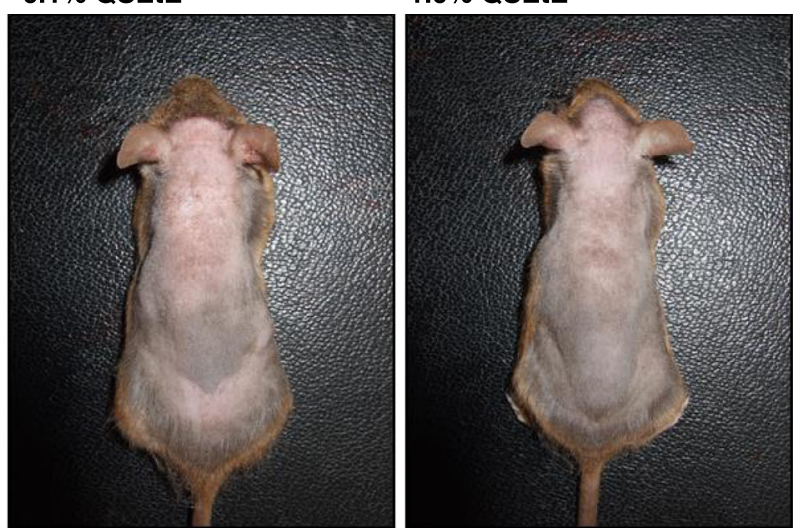

Fig. 2 Effect of QSEtE pretreatment on the development of atopic dermatitis-like skin lesions in NC/Nga mice. a Clinical skin severity score. Clinical skin severity scores of mice were measured on day 0 , and every 7 days after, of the experimental period. Clinical scores are expressed as the mean \pm standard deviation ( $n=6$ per group). ${ }^{*} P<0.05$ and ${ }^{* * *} P<0.001$ vs. vehicle group (Mann-Whitney's $\cup$ test). b Biostir-AD-induced skin lesions in dorsal skin. Photographs were taken on the last day (day 28) of the experimental period 


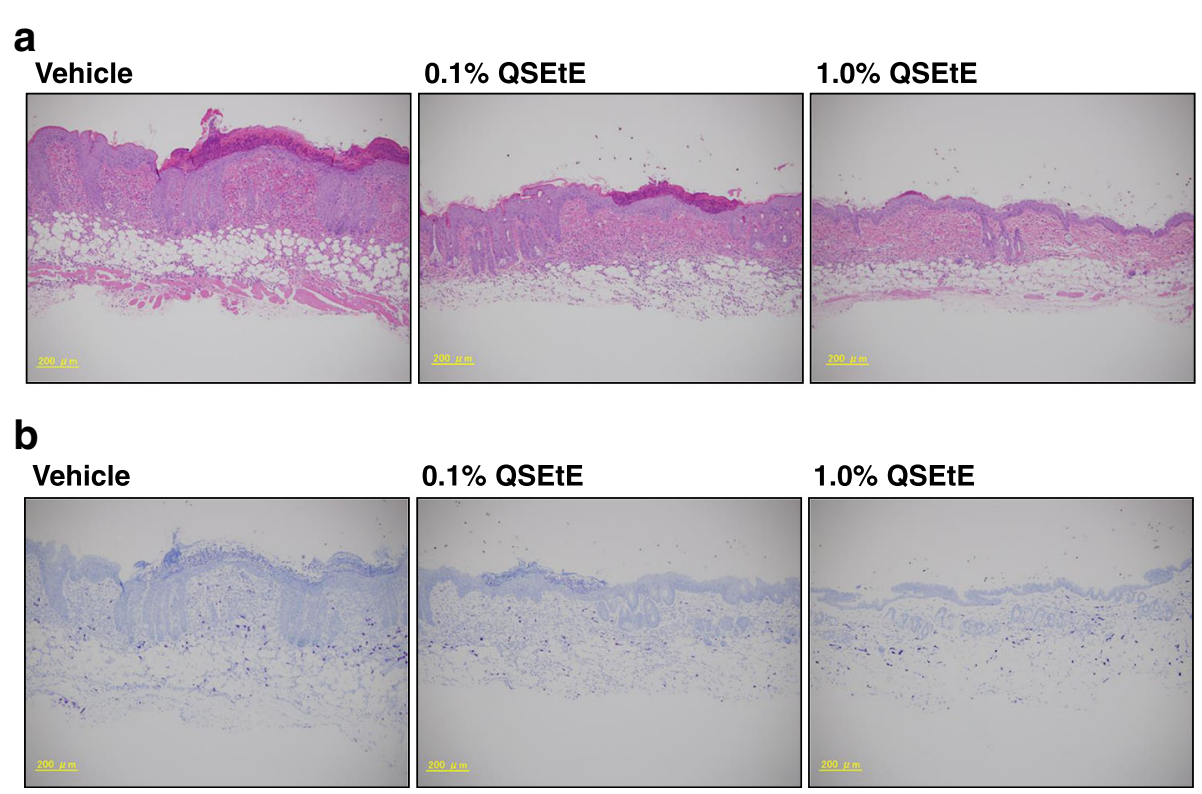

Fig. 3 Effect of QSEtE pretreatment on skin lesions in NC/Nga mice. a Hematoxylin and eosin-stained dorsal skin lesions. b Toluidine blue-stained dorsal skin lesions. The histological images were taken on the last day (day 28) of the experimental period

Effect of QSEtE on serum total IgE levels of NC/Nga mice The IgE levels in the serum of mice are shown in Fig. 4. Serum total IgE levels of mice in the vehicle group, $0.1 \%$ QSEtE group, and 1.0\% QSEtE group were approximately $3418 \mathrm{ng} / \mathrm{mL}, 2108 \mathrm{ng} / \mathrm{mL}$, and $1895 \mathrm{ng} / \mathrm{mL}$, respectively. IgE levels in $0.1 \%$ QSEtE and 1.0\% QSEtE group were significantly lower $(P<0.01)$ than those of the vehicle group.
Effect of QSEtE on TARC expression in the dorsal skin of $\mathrm{NC} / \mathrm{Nga}$ mice

The TARC expression level in the dorsal skin of mice is shown in Fig. 5. Topical application of QSEtE at the concentrations of 0.1 and $1.0 \%$ reduced TARC expression by approximately 41 and $47 \%$, respectively. These reductions were significant in comparison with those observed for the vehicle mice $(P<0.01$ and $P<0.001$, respectively).

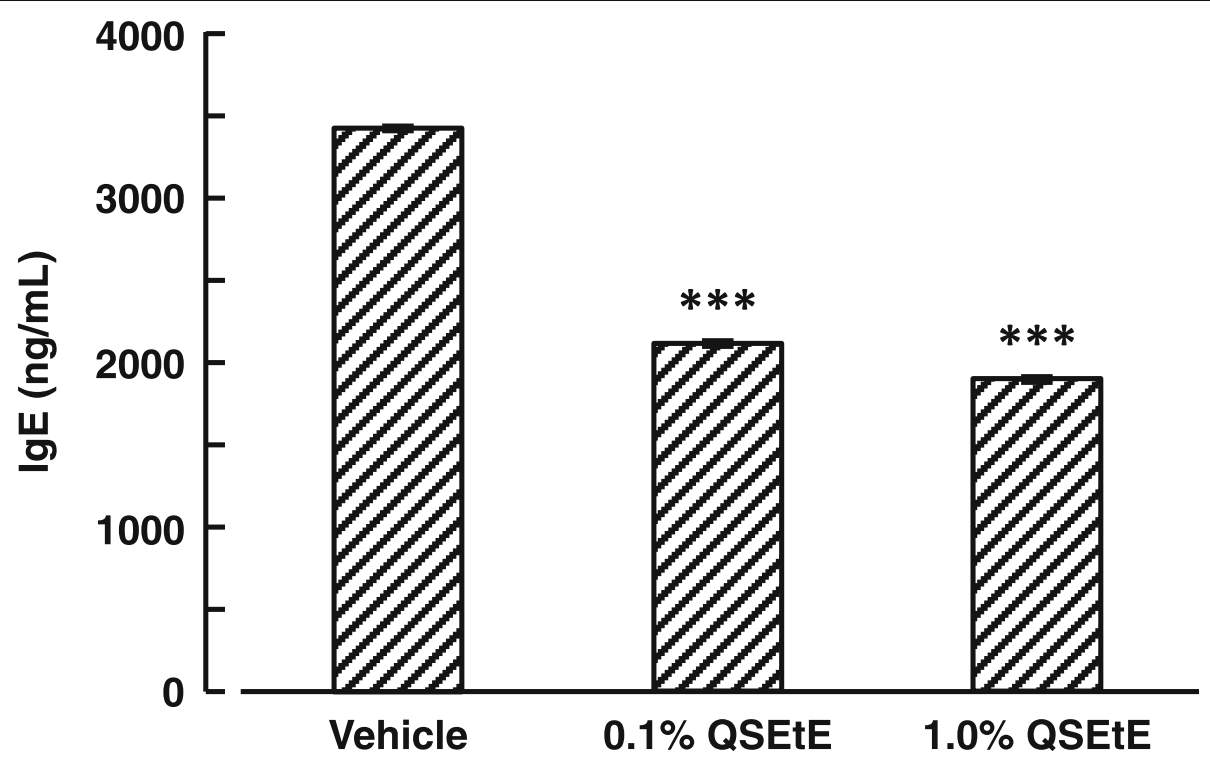

Fig. 4 Effect of QSEtE on serum total lgE levels of NC/Nga mice. Blood samples were collected on the last day (day 28) of the experimental period. Data are expressed as the mean \pm standard error $(n=3) .{ }^{* * *} P<0.001 \mathrm{vs}$. vehicle group (Student's t-test) 


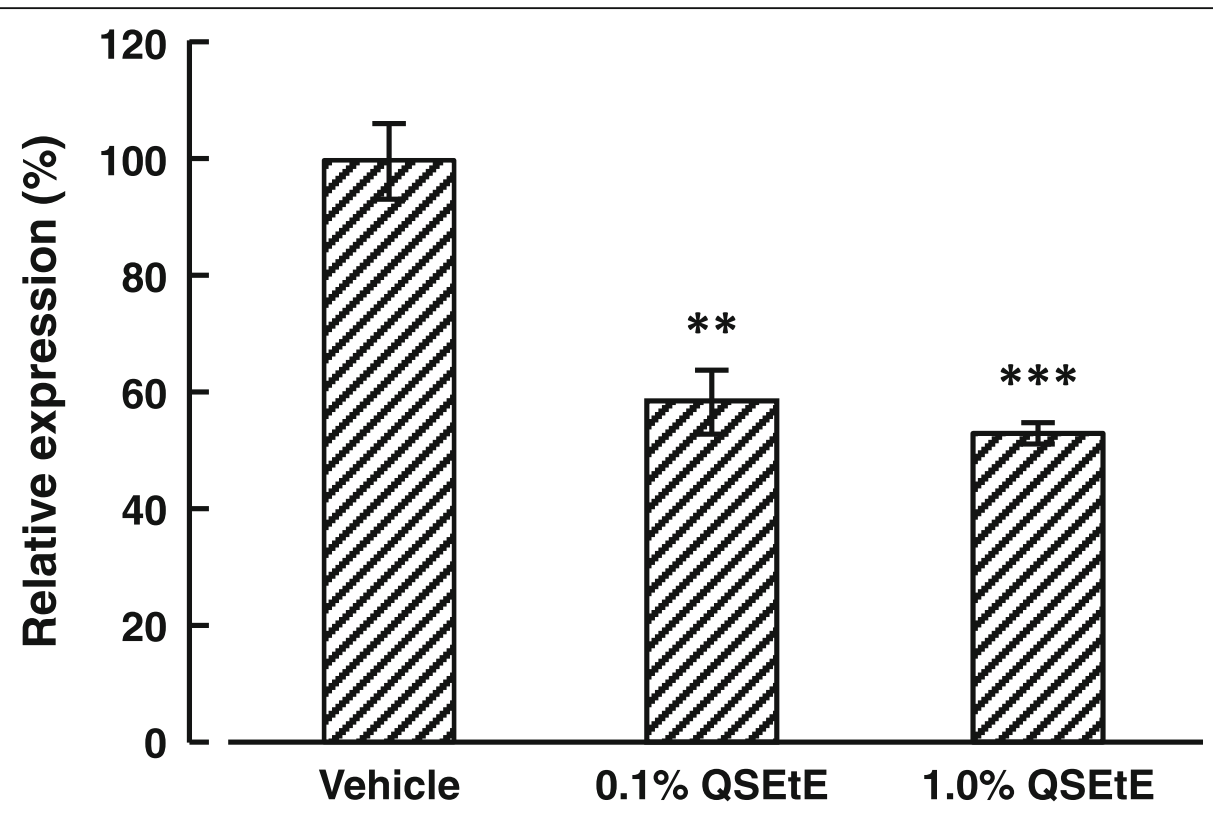

Fig. 5 Effect of QSEtE treatment on TARC expression in dorsal skin of NC/Nga mice. Dorsal skin was harvested on the last day (day 28) of the experimental period. Data are expressed as the mean \pm standard error $(n=3) .{ }^{* *} P<0.01$ and ${ }^{* * *} P<0.001$ vs. vehicle group (Student's t-test)

\section{Effect of QSEtE treatment on TNF- $\alpha$ - and IFN- $\gamma$-induced} TARC expression in HaCaT cells

$\mathrm{HaCaT}$ cells stimulated with TNF- $\alpha$ and IFN- $\gamma$ demonstrated increased TARC expression levels compared with those reported for unstimulated cells as described previously [14]. QSEtE (456, 913, 1825, 3650 or $7300 \mathrm{ng} / \mathrm{mL}$ ) suppressed TNF- $\alpha$ - and IFN- $\gamma$-induced TARC expression in a dose-dependent manner (Fig. 6a). Moreover, TARC protein secreted in the supernatant of cells was significantly suppressed by QSEtE at $14,600 \mathrm{ng} / \mathrm{mL}(P<0.01$; Fig. 6b). Under our culture conditions, no significant difference in the proliferation and viability of $\mathrm{HaCaT}$ cells was observed at QSEtE concentrations $\leq 40,000 \mathrm{ng} / \mathrm{mL}$ (data not shown).

\section{Discussion}

AD often causes a disturbance of the epidermal-barrier function, resulting in dry skin and immune responses against environmental allergens [15]. Various factors are involved in the pathogenesis and development of AD. In particular, house dust mite allergens are considered to be the most common cause of AD [16]. In fact, extracts from $D$. farinae, a common house dust mite, cause ADlike eczematous skin lesions in NC/Nga mice [17]. In the present study, we investigated the effect of QSEtE on house dust mite-induced AD-like skin lesions in $\mathrm{NC} /$ Nga mice.

Throughout this study, we demonstrated that QSEtE pre-treatment dramatically reduced subsequently induced dermatitis symptoms (Figs. 2 and 3a), mast cell infiltration (Fig. 3b), and serum IgE level (Fig. 4). In addition, we showed that TARC expression decreased in skin lesions in mice (Fig. 5), and in in vitro cultures of HaCaT cells (Fig. 6).

TARC, also known as CC chemokine ligand 17, is a member of $\mathrm{C}-\mathrm{C}$ chemokine family and is mainly produced by keratinocytes, dendritic cells, endothelial cells and fibroblasts [18]. Previous studies showed that TARC acts as a chemoattractant that guides Th2 cells that highly express CC chemokine receptor (CCR) 4 and CCR8 [19, 20]. Th2 cells produce chemokines, such as RANTES, a potent chemoattractant for memory-type cluster of differentiation $4 \mathrm{~T}$ cells, eosinophils and mast cells, which results in Th2-skewed atopic inflammation [21]. When NC/Nga mice develop AD-like lesions, TARC is overproduced by the keratinocytes in skin lesions, but not in the skin without lesions [22].

In addition, TARC is produced by keratinocytes and has been shown to accelerate inflammatory responses in the skin of human AD patients [23]. In many cases, the serum level of TARC is elevated in patients with $A D$, and is closely associated with the disease activity of $\mathrm{AD}$ [24-26]. Therefore, TARC is recognized as a therapeutic target in the treatment of allergic disorders [27, 28]. Our results suggest the involvement of the suppressive effect of QSEtE on atopic symptoms and TARC production in the skin lesions of $\mathrm{NC} / \mathrm{Nga}$ mice.

As shown in Fig. 4, we also found that serum levels of IgE were significantly suppressed in the group receiving topical application of QSEtE as compared with that reported for the vehicle-treated group. Although the mechanism of IgE suppression by QSEtE remains 


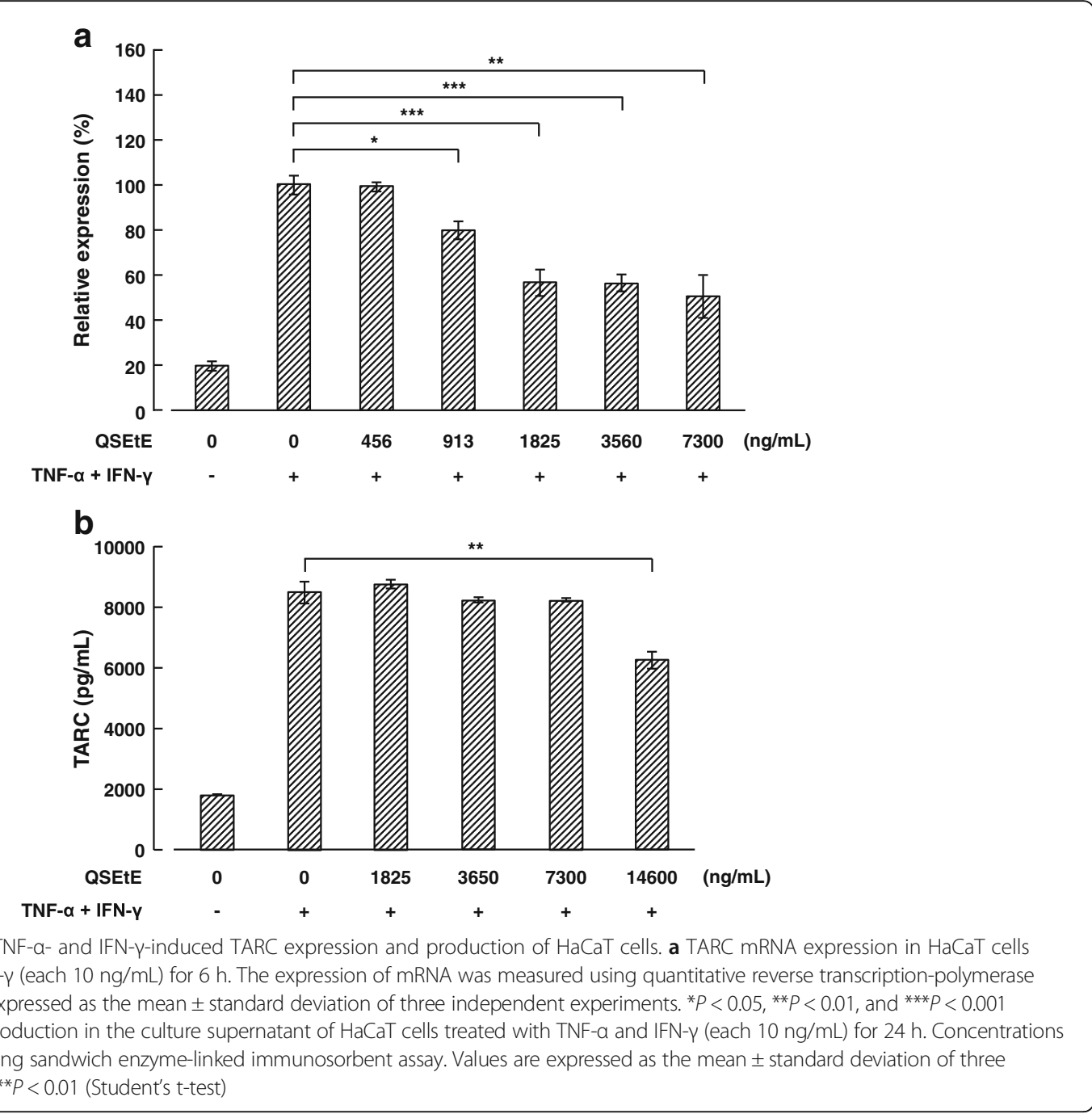

unclear, Jung et al. [29] reported that TARC-suppressive phenolic compounds ameliorated AD symptoms accompanied by the suppression of serum IgE. In general, synthesis of IgE by B cells is stimulated by various Th2 cell-derived cytokines such as IL-4, IL-5 and IL-13 $[30,31]$. Elevated IgE eventually results in the development of AD-like skin lesions by mediating mast cell degranulation. IgE-associated mast cell degranulation releases inflammatory mediators such as histamine, which increases blood vessel permeability, thus facilitating immune cell migration from the circulation to the affected tissue, resulting in aggravation of AD symptoms [32]. Therefore, we hypothesize that the suppression of TARC in lesion site by QSEtE may suppress the of mast cell recruitment and improve Th1/Th2 immune balance to downregulate IgE production, resulting in the alleviation of IgE- and mast cell-related atopic symptoms. In this study, we did not determine the components responsible for the anti-atopic effect of QSEtE. However, it should be noted that QSEtE could easily pass through the sterilizing filter easily, which was different from the property of water-soluble quince seed mucilage. Additional studies are needed to identify the primary active components of QSEtE

\section{Conclusions}

In conclusion, we showed that the topical application of QSEtE reduced the development of house dust mite allergen-induced skin lesions in NC/Nga mice. In addition, in vitro evaluations showed that QSEtE directly suppressed TARC expression and the production of keratinocytes. Although the results obtained from NC/Nga mice would be difficult to directly extrapolate to humans owing to genetic heterogeneity of humans, the ability of QSEtE to suppress TARC from keratinocytes may have a role in its effectiveness for treating AD. We believe that QSEtE could be a good candidate to protect the skin from allergen-induced Th2type inflammation in the onset and development of $\mathrm{AD}$. 


\section{Abbreviations}

AD: Atopic dermatitis; CCR: CC chemokine receptor; GAPDH: Glyceraldehyde3-phosphate dehydrogenase; QSEtE: Ethanol extract of quince seeds; TARC: Thymus and activation-regulated chemokine

\section{Acknowledgements}

None.

\section{Funding}

The authors declare that they have received no funding for the research reported.

\section{Availability of data and materials}

Accession numbers and their databases have been mentioned in the manuscript.

\section{Authors' contributions}

This study was designed and conducted by TK, YH and TI. KT and EN participated in preparation of samples and data analyses. The manuscript was prepared by TK. All authors have read and approved the final manuscript.

\section{Competing interests}

The authors declare that they have no competing interests.

\section{Consent for publication}

Not applicable.

\section{Ethics approval}

All animal experiments were approved by the Committee for Animal Experiments of Shinshu University.

\section{Author details}

'Department of Sciences of Functional Foods, Graduate School of Agriculture, Shinshu University, 8304 Minamiminowa, Kamiina, Nagano 399-4598, Japan. ${ }^{2}$ Research Center for Fungal \& Microbial Dynamism, Shinshu University, 8304 Minamiminowa, Kamiina, Nagano 399-4598, Japan. ${ }^{3} J u p o n$ International, 4-31-5 Nishikojiya, Ota-ku, Tokyo 144-0034, Japan.

Received: 17 November 2016 Accepted: 26 January 2017

Published online: 31 January 2017

\section{References}

1. Ganopoulos I, Merkouropoulos G, Pantazis S, Tsipouridis C, Tsaftaris A. Assessing molecular and morpho-agronomical diversity and identification of ISSR markers associated with fruit traits in quince (Cydonia oblonga). Genet Mol Res. 2011:10(4):2729-46.

2. Schreyen L, Dirinck P, Sandra P, Schamp N. Flavor analysis of quince. J Agric Food Chem. 1979;27(4):872-6.

3. Smith F, Montgomery R. The chemistry of plant gums and mucilages. New York: Reinhold Publishing Corporation; 1959.

4. Ghafourian M, Tamri P, Hemmati A. Enhancement of human skin fibroblasts proliferation as a result of treating with quince seed mucilage. Jundishapur Nat Pharm Prod. 2015;10(1):e18820.

5. Tamri $P$, Hemmati A, Boroujerdnia MG. Wound healing properties of quince seed mucilage: in vivo evaluation in rabbit full-thickness wound model. Int J Surg. 2014;12(8):843-7

6. Hemmati AA, Kalantari $\mathrm{H}$, Jalali A, Rezai S, Zadeh HH. Healing effect of quince seed mucilage on T-2 toxin-induced dermal toxicity in rabbit. Exp Toxicol Pathol. 2012;64(3):181-6.

7. Grieve M. A Modern Herbal: the medicinal, culinary, cosmetic and economic properties, cultivation and folklore of herbs, grasses, fungi, shrubs, and trees with all their modern scientific uses. New York: Dover Publications; 1971.

8. Williams HC. Epidemiology of atopic dermatitis. Clin Exp Dermatol. 2000; 25(7):522-9.

9. Coombs RRA, Gell PGH. "Clinical aspects of immunology" 2nd ed. Oxford: Blackwell Science Publication; 1968. p. 575-96.

10. Imai T, Nagira M, Takagi S, Kakizaki M, Nishimura M, Wang J, Gray PW, Matsushima K, Yoshie O. Selective recruitment of CCR4-bearing Th2 cells toward antigen-presenting cells by the CC chemokines thymus and activation-regulated chemokine and macrophage-derived chemokine. Int Immunol. 1999;11(1):81-8.
11. Yamamoto M, Haruna T, Yasui K, Takahashi H, Iduhara M, Takaki S, Deguchi M, Arimura A. A novel atopic dermatitis model induced by topical application with Dermatophagoides farinae extract in NC/Nga mice. Allergol Int. 2007;56(2):139-48.

12. Sumiyoshi K, Nakao A, Setoguchi $Y$, Tsuboi R, Okumura K, Ogawa H. TGFbeta/Smad signaling inhibits IFN-gamma and TNF-alpha-induced TARC (CCL17) production in HaCaT cells. J Dermatol Sci. 2003;31(1):53-8.

13. Kawahara T, Nakayama D, Tanaka K, Yasui H. Effect of oral administration of the IgE-suppressive wild yeast strain Saccharomyces paradoxus P01 on the development of atopic dermatitis-like symptoms in NC/Nga mice. Food Sci Technol Res. 2015;21(2):223-30.

14. Vestergaard C, Kirstejn N, Gesser B, Mortensen JT, Matsushima K, Larsen CG. IL-10 augments the IFN- $\gamma$ and TNF- $a$ induced TARC production in $\mathrm{HaCaT}$ cells: a possible mechanism in the inflammatory reaction of atopic dermatitis. J Dermatol Sci. 2001;26:46-54.

15. Leung DY, Bieber T. Atopic dermatitis. Lancet. 2003;361(9352):151-60.

16. Lee HH, Ahn JH, Kwon AR, Lee ES, Kwak JH, Min YH. Chemical composition and antimicrobial activity of the essential oil of apricot seed. Phytother Res. 2014;28(12):1867-72

17. Matsuoka H, Maki N, Yoshida S, Arai M, Wang J, Oikawa Y, Ikeda T, Hirota N, Nakagawa $\mathrm{H}$, Ishii A. A mouse model of the atopic eczema/dermatitis syndrome by repeated application of a crude extract of house-dust mite Dermatophagoides farinae. Allergy. 2003:58(2):139-45.

18. Saeki H, Tamaki K. Thymus and activation regulated chemokine (TARC)/ CCL17 and skin diseases. J Dermatol Sci. 2006:43(2):75-84.

19. Imai T, Baba M, Nishimura M, Kakizaki M, Takagi S, Yoshie O. The T celldirected CC chemokine TARC is a highly specific biological ligand for CC chemokine receptor 4. J Biol Chem. 1997;272(23):15036-42.

20. Bernardini G, Hedrick J, Sozzani S, Luini W, Spinetti G, Weiss M, Menon S, Zlotnik A, Mantovani A, Santoni A, Napolitano M. Identification of the CC chemokines TARC and macrophage inflammatory protein-1 beta as novel functional ligands for the CCR8 receptor. Eur J Immunol. 1998;28(2):582-8.

21. Mattoli S, Ackerman V, Vittori E, Marini M. Mast cell chemotactic activity of RANTES. Biochem Biophys Res Commun. 1995:209(1):316-21.

22. Vestergaard C, Yoneyama H, Murai M, Nakamura K, Tamaki K, Terashima $Y$, Imai T, Yoshie O, Irimura T, Mizutani H, Matsushima K. Overproduction of Th2-specific chemokines in NC/Nga mice exhibiting atopic dermatitis-like lesions. J Clin Invest. 1999:104(8):1097-105.

23. Vestergaard C, Bang K, Gesser B, Yoneyama H, Matsushima K, Larsen CG. A Th2 chemokine, TARC, produced by keratinocytes may recruit CLA + CCR4+ lymphocytes into lesional atopic dermatitis skin. J Invest Dermatol. 2000; 115(4):640-6.

24. Kakinuma T, Nakamura K, Wakugawa M, Mitsui H, Tada Y, Saeki H, Torii H, Asahina A, Onai N, Matsushima K, Tamaki K. Thymus and activationregulated chemokine in atopic dermatitis: Serum thymus and activationregulated chemokine level is closely related with disease activity. J Allergy Clin Immunol. 2001;107(3):535-41.

25. Horikawa T, Nakayama T, Hikita I, Yamada H, Fujisawa R, Bito T, Harada S, Fukunaga A, Chantry D, Gray PW, Morita A, Suzuki R, Tezuka T, Ichihashi M, Yoshie O. IFN-yinducible expression of thymus and activation-regulated chemokine/CCL17 and macrophage-derived chemokine/CCL22 in epidermal keratinocytes and their roles in atopic dermatitis. Int Immunol. 2002;14(7):767-73.

26. Kataoka Y. Thymus and activation-regulated chemokine as a clinical biomarker in atopic dermatitis. J Dermatol. 2014;41(3):221-9.

27. Herz U, Bunikowski R, Renz H. Role of T cells in atopic dermatitis. New aspects on the dynamics of cytokine production and the contribution of bacterial superantigens. Int Arch Allergy Immunol. 1998;115(3):179-90.

28. Takeuchi $\mathrm{H}$, Yamamoto $\mathrm{Y}$, Kitano $\mathrm{H}$, Enomoto $\mathrm{T}$. Changes in thymus- and activation-regulated chemokine (TARC) associated with allergen immunotherapy in patients with perennial allergic rhinitis. J Investig Allergol Clin Immunol. 2005;15(3):172-6

29. Jung MK, Hur DY, Song SB, Park Y, Kim TS, Bang SI, Kim S, Song HK, Park H, Cho DH. Tannic acid and quercetin display a therapeutic effect in atopic dermatitis via suppression of angiogenesis and TARC expression in Nc/Nga mice. J Invest Dermatol. 2010;130(5):1459-63.

30. Pène J, Rousset F, Brière F, Chrétien I, Wideman J, Bonnefoy JY, De Vries JE. Interleukin 5 enhances interleukin 4-induced lgE production by normal human B cells. The role of soluble CD23 antigen. Eur J Immunol. 1988;18(6):929-35.

31. de Vries JE. The role of IL-13 and its receptor in allergy and inflammatory responses. J Allergy Clin Immunol. 1998;102(2):165-9.

32. Krystel-Whittemore M, Dileepan KN, Wood JG. Mast cell: a multi-functional master cell. Front Immunol. 2015;6:620. 